\title{
Adverse health effects of low levels of perceived control in Swedish and Russian community samples Johanna Lundberg${ }^{1}$, Martin Bobak ${ }^{2}$, Sofia Malyutina ${ }^{3}$, Margareta Kristenson ${ }^{1}$ and Hynek Pikhart*2
}

Address: ${ }^{1}$ Department of Medical and Health Sciences, Linköping University, Sweden, ${ }^{2}$ International Institute for Society and Health, Department of Epidemiology and Public Health, UCL, London, UK and 'Institute of Internal Medicine, Russian Academy of Medical Sciences, Novosibirsk, Russia

Email: Johanna Lundberg - johanna.lundberg@ihs.liu.se; Martin Bobak -m.bobak@ucl.ac.uk; Sofia Malyutina - smalyutina@hotmail.com; Margareta Kristenson - margareta.kristenson@ihs.liu.se; Hynek Pikhart* - h.pikhart@ucl.ac.uk

* Corresponding author

Published: 2 November 2007

BMC Public Health 2007, 7:314 doi:10.1 I86/147|-2458-7-3/4
Received: 4 May 2007

Accepted: 2 November 2007

This article is available from: http://www.biomedcentral.com/I47I-2458/7/3/4

(c) 2007 Lundberg et al; licensee BioMed Central Ltd.

This is an Open Access article distributed under the terms of the Creative Commons Attribution License (http://creativecommons.org/licenses/by/2.0), which permits unrestricted use, distribution, and reproduction in any medium, provided the original work is properly cited.

\begin{abstract}
Background: This cross-sectional study of two middle-aged community samples from Sweden and Russia examined the distribution of perceived control scores in the two populations, investigated differences in individual control items between the populations, and assessed the association between perceived control and self-rated health.
\end{abstract}

Methods: The samples consisted of men and women aged 45-69 years, randomly selected from national and local population registers in southeast Sweden $(n=1007)$ and in Novosibirsk, Russia $(n=923 \mathrm{I})$. Data were collected by structured questionnaires and clinical measures at a visit to a clinic. The questionnaire covered socioeconomic and lifestyle factors, societal circumstances, and psychosocial measures. Self-rated health was assessed by standard single question with five possible answers, with a cut-off point at the top two alternatives.

Results: $32.2 \%$ of Swedish men and women reported good health, compared to $10.3 \%$ of Russian men and women. Levels of perceived control were also significantly lower in Russia than in Sweden and varied by socio-demographic parameters in both populations. Sub-item analysis of the control questionnaire revealed substantial differences between the populations both in the perception of control over life and over health. Logistic regression analysis revealed that the odds ratios (OR) of poor self-rated health were significantly increased in men and women with low perceived control in both countries (OR between $2.6 \mathrm{I}$ and 4.26).

Conclusion: Although the cross-sectional design does not allow causal inference, these results support the view that perceived control influences health, and that it may mediate the link between socioeconomic hardship and health.

\section{Background}

In the second half of the $20^{\text {th }}$ century, health status has declined in Central and Eastern Europe, resulting in decreasing life expectancies, while health status in Western Europe has improved [1-3]. Among the former communist countries, Russia experienced the most dramatic 
decline in life expectancy, particularly during the 1990s, resulting in a near 20-year difference to Swedish men [4]. As an illustration, life expectancy in Russia was 58.9 years for men and 71.8 years among women in 2001, comprising 3 million more middle-age deaths than if rates would be based on 1991 mortality rates [4]. Also, measures of self-rated health and physical functioning are significantly lower compared to Swedish rates, for both men and women $[5,6]$. These differences have not been explained by environment or lifestyle factors, and have generated an interest in other risk factors, such as psychosocial factors [1]. The general impact of psychosocial factors on health has been illustrated by Kristenson et al [7] who have shown, on the example of the high CHD mortality rates in Lithuania, how levels of vital exhaustion (a measure of extended physical and mental fatigue) and depression were substantially higher in Lithuania than among Swedish middle-aged men.

An important psychosocial factor, though not wellexplored in terms of East-West comparisons, is perceived control, which represents individuals' perceptions of the magnitude of power over their own lives [8-13]. This concept is closely related to other concepts of individual psychological characteristics, such as coping ability, mastery, self-esteem and internal locus of control, which all relate to peoples learned outcome expectancies [14]. Measures of perceived control have proved to be a robust predictor of mental and physical well-being and of all-cause mortality [15], and perceived control has been shown to explain a substantial part of SES differences in mortality in cohort studies $[16,17]$. Low control over life was further found to account for the negative impact of low social position on health, while good family relations protected against poor health [16]. Carlson [6] points to the fact that a sense of life control is important for people's self-perceived health in almost every European country, but that in the former communist countries, control levels are generally lower than in the west. In cross-sectional studies, low perceived control has been shown to be related to low self-rated health as an independent factor in Eastern Europe $[12,13]$. Deprivation and low perceived control were here suggested as important mediators in the relation between social circumstances and health.

Furthermore, the East-West health gap seems to follow the same gradient that has repeatedly been found across the social spectrum in almost every modern society, stating that the lower the socioeconomic status (SES), the worse the health status $[1,18,19]$. Not only do relative differences between countries seem to matter, but also relative differences within each population are important. Just as the East - West differences, these variations in life expectancy and health can only partly be explained by lifestyle factors, such as smoking, alcohol intake, poor diet and poor exercise habits $[1,12,18,20]$. Psychosocial factors have been proposed to explain at least part of social gradients in health in western Europe and United States $[11,21,22]$. Gilmore, McKee \& Rose [23] demonstrated that SES including a poor material situation as well as psychosocial factors, among them low control over life, were independent determinants of self-rated health in Ukraine.

The vast societal changes in post-communist countries since the beginning of the 1990's resulted in growing inequalities in income distribution along with material deprivation, and in the collapse of social institutions $[6,12,24-26]$. The health impact of these changes, emanating from the relationships between individual needs, the social structure and the psychosocial environment, should be of importance for further studies. Earlier findings imply that low levels of control are likely to contribute to the poor health situation following transition in Russia [12]. We therefore see perceived control as an important focus for East-West comparative studies. Comparing populations in different political and cultural settings, such as Sweden and Russia, could provide valuable knowledge on the intrusiveness of psychosocial factors on health, as well as to shed light on the importance of relative position and social status within populations.

Our aim is to investigate levels in the perception of life control among men and women in community samples of Swedish and a Russian population, and to assess whether these measures are associated with self-rated health in each of the studied communities. We also aim at identifying socio-demographic differences related to perceived control, within and between the populations, and to explore differences in answer patterns to the perceived control questionnaire.

\section{Methods}

\section{Populations and subjects}

This paper uses data from two related studies, both originally designed to enable comparative analyses by a common sampling strategy and a common study protocol for a core battery of parameters: The Swedish LSH study (Life conditions, Stress, and Health) and the HAPIEE study (Health, Alcohol and Psychosocial Factors in Eastern Europe) [27]. Both studies are still ongoing, and followup data collections are currently in process. The current analysis is based on the baseline data collection.

For the Swedish LSH Study, the baseline data were collected during 2003-2004. Participants were 1007 men and women aged 45-69 years in 2003, stratified by 5-year age groups, and belonging to any of the catchment areas of 10 primary health care centres in southeast Sweden (response rate 62\%). Participants fulfilling these requirements were randomly selected via the National popula- 
tion register. Data collection at baseline included selfreported data via postal questionnaires, and measures of blood pressure, anthropometrics and blood sampling during a visit to a local clinic. Exclusion criteria were serious disease and difficulties in understanding the language. The study population is nationally representative in terms of age, civil status and educational level.

The Russian data come from the baseline phase of the Russian part of the HAPIEE study in 2002-2005. A sample of men and women 45-69 years old, stratified by gender and 5-year age groups, was randomly chosen from local population register of Novosibirsk town, and selected individuals were invited to participate in the study. The data analysed in this report were collected by a structured questionnaire and by the examination at local clinics; 9231 men and women aged 45-69 years participated in the baseline examination (response rate 61\%). The study population is representative for Russian urban population in terms of age, sex and educational level.

\section{Measurements}

The structured questionnaires in both countries contained a common set of identical core parameters that cover a broad amount of topics, such as socioeconomic status, a section on psychosocial measures, health behaviours, selfrated health and diagnosed illnesses. All questionnaires were administered by mail in Sweden, while in Russia participants needed to visit the clinic in order to fill in the questionnaires. Correct wording was checked by translating both, Swedish and Russian, questionnaires back into English.

A score of perceived control was based on agreement or disagreement with eleven statements adapted from the Whitehall II Study [9], MacArthur Foundation programme on Midlife development [10] and the New Barometer studies $[12,13]$. They are similar to the questions on perceived constraints used and extensively validated by Lachman and Weaver in the US [11]. Lachman [28] reviewed use of sense of control measures in midlife studies. Use of this instrument in Russia and six other post-communist countries was validated by Bobak et al [13]. Exact wording of used questions is presented in one of the tables. Items 2, 3 and 4 are generally seen as representing "control over health" while the other items represent "control over life". The subjects were asked to what extent they agree or disagree with the statements. The answers were recorded at a six-point scale (coded as 0-5). Scores were calculated if a minimum of 9 out of 11 questions contained valid answers. If less than 11 valid answers, the score was divided by the number of valid answers and then multiplied by 11 . The final score ranged between 0 (no control) and 55 (maximum control). Internal consistency as assessed by Cronbach's alpha was 0.66 and 0.71 for Swedish men and women, and 0.64 and 0.63 for Russian men and women. We have also constructed two subscales, control over health and control over life, and assessed their internal consistency. Internal consistency of subscales was not better than of the whole scale: Cronbach's alpha for health control ranged between 0.60 and 0.66 and for life control between 0.60 and 0.69 when separately calculated for Swedish and Russian men and women.

Self-rated health [29] was assessed by a standard single question with answers on a 5-point scale. For the analysis, the dichotomized outcome was defined as the top two categories representing good health, while poor health was defined as the bottom three categories.

The characteristics used in different stages of analysis included: civil status, education, body mass index (BMI), total cholesterol, blood pressure measurement and smoking. Civil status was classified into 4 categories: married/ cohabiting, single, divorced and widowed. Education was classified into 3 categories: primary or less, secondary/ vocational and completed university. BMI was calculated from measures obtained at the clinical investigation. Serum concentrations of total cholesterol were obtained from blood collected at the clinical examination. Measurements of blood pressure were collected also at the clinical examination. Smoking was assessed through four options: never smoked, have quit smoking, smoke less than 1 cigarette/day, smoke regularly at least 1 cigarette/ day, where the latter two were categorized into "regular smoker".

\section{Statistical analysis}

Distributions of background factors and self-rated health were calculated for both populations, and were also stratified by sex within the two countries. For comparative purposes, means and distributions of perceived control were calculated for each country separately. Logistic regression was used to analyse the associations between psychosocial factors and self-rated health, firstly controlling for age only, and secondly controlling for age, education, civil status, obesity (in terms of BMI), blood pressure, cholesterol levels, and smoking. All analyses were conducted separately for men and women for each of the study populations. A p-value of $<0.05$ was regarded as significant.

\section{Results \\ Demographics}

Descriptive characteristics of the two samples are presented in Table 1. The two samples are similar in terms of age groups and with regards to the proportion of women and men. Three times as many Russian women (14.5\%) were divorced, compared to Russian men (5.5\%). Among the Swedish women and men, rates were lower and more 
Table I: Descriptive characteristics of LSH and HAPIEE participants

\begin{tabular}{|c|c|c|c|c|c|c|}
\hline & \multicolumn{3}{|c|}{ Sweden } & \multicolumn{3}{|c|}{ Russia } \\
\hline & Total $(n=1007)$ & Men $(n=502)$ & Women $(n=505)$ & Total $(n=9231)$ & Men $(n=420 I)$ & Women $(n=5030)$ \\
\hline Age group & $\%$ & $\%$ & $\%$ & $\%$ & $\%$ & $\%$ \\
\hline $45-49$ & 19.7 & 19.7 & 19.6 & 17.0 & 15.8 & 18.0 \\
\hline $50-54$ & 20.2 & 20.1 & 20.2 & 19.6 & 19.9 & 19.3 \\
\hline $55-59$ & 20.4 & 20.7 & 20.0 & 21.7 & 21.8 & 21.6 \\
\hline $60-64$ & 19.8 & 19.7 & 19.8 & 19.2 & 19.5 & 19.0 \\
\hline $65-69$ & 20.1 & 19.7 & 20.4 & 22.5 & 22.9 & 22.1 \\
\hline \multicolumn{7}{|l|}{ Civil status } \\
\hline Single & 6.6 & 6.5 & 6.7 & 3.8 & 2.7 & 4.7 \\
\hline Married/cohabiting & 82.5 & 86.3 & 78.6 & 72.3 & 87.8 & 59.4 \\
\hline Divorced & 7.5 & 6.3 & 8.8 & 10.5 & 5.5 & 14.5 \\
\hline Widowed & 3.4 & 0.8 & 5.9 & 13.4 & 4.0 & 21.3 \\
\hline \multicolumn{7}{|l|}{ Education } \\
\hline Primary & 35.6 & 36.4 & 34.8 & 10.3 & 11.2 & 9.5 \\
\hline Secondary & 43.2 & 43.1 & 43.4 & 60.8 & 56.8 & 64.1 \\
\hline University & 21.2 & 20.5 & 21.7 & 28.9 & 32.0 & 26.4 \\
\hline \multicolumn{7}{|l|}{ Smoking } \\
\hline Non-smoker & 42.4 & 38.1 & 46.7 & 58.1 & 25.7 & 85.2 \\
\hline Ex-smoker & 38.6 & 42.7 & 34.4 & 13.6 & 24.5 & 4.3 \\
\hline Regular smoker & 19.0 & 19.2 & 18.9 & 28.3 & 49.8 & 10.5 \\
\hline \multicolumn{7}{|l|}{ Self-rated health } \\
\hline I (very good) & 8.2 & 8.7 & 7.6 & 0.2 & 0.2 & 0.2 \\
\hline 2 & 24.0 & 27.4 & 20.6 & 10.1 & 15.5 & 5.6 \\
\hline 3 & 41.0 & 41.6 & 40.3 & 67.4 & 67.5 & 67.2 \\
\hline 4 & 22.5 & 19.5 & 25.5 & 20.8 & 15.8 & 24.9 \\
\hline 5 (very poor) & 4.4 & 2.8 & 6.0 & 1.6 & 1.0 & 2.1 \\
\hline
\end{tabular}

equal ( $8.8 \%$ vs. $6.3 \%$ ). While $21.3 \%$ of Russian women were widowed, this was the case for just $4.0 \%$ of Russian men. For Swedish men and women, rates were $0.8 \%$ and $5.9 \%$. Russians reported to a higher extent a university degree than did Swedes (28.9\% vs. $21.2 \%$ ), while also presenting lower rates of primary education only $(10.3 \%$ vs. $35.6 \%$ ). These differences remain within both sexes when comparing the populations. $49.8 \%$ of Russian men reported smoking regularly, compared to just $10.5 \%$ of Russian women. Among the Swedes, about a fifth of the population reported regular smoking (same share for both sexes). Mean BMI (not presented in table) values ranged from 26.5 to 30 with Russian women counting the highest mean level.

\section{Self-rated health}

Self-rated health was assessed by a standard single question with answers on a 5-point scale, with the top two categories set as representing "good health". Rates for good health in the Swedish population were clearly higher than in the Russian population (32.2\% vs. 10.3\%). Almost none of the Russians reported the top alternative, "very good health" $(0.2 \%)$, while $8.2 \%$ of Swedes did this. Swedish women report good health to a lesser extent than do Swedish men (28.2\% vs. 36.1\%), and Russian women score not only lower than Russian men (5.8\% vs. $15.7 \%$ ), but also present the lowest scores of all four groups. In general, women in both populations show a tendency to report scores at the lower end of the scale more than men do.

\section{Perceived control}

The mean control scores were higher in the Swedish population. For Swedish men, the mean control score was 40.6, while for Russian men it was 34.5 (Table 2). For Swedish women, the mean score was 39.0 , compared to 33.6 for Russian women (for both sexes $\mathrm{p}<0.001$ for differences in control scores between 2 countries). Figure 1 shows cumulative frequency of perceived control score. Lower control scores among Russians can be seen across whole sample distribution. Control levels showed a linear relation to educational status within both populations, but the scores also formed a social gradient across the countries, as the highest scores were seen with highly edu- 


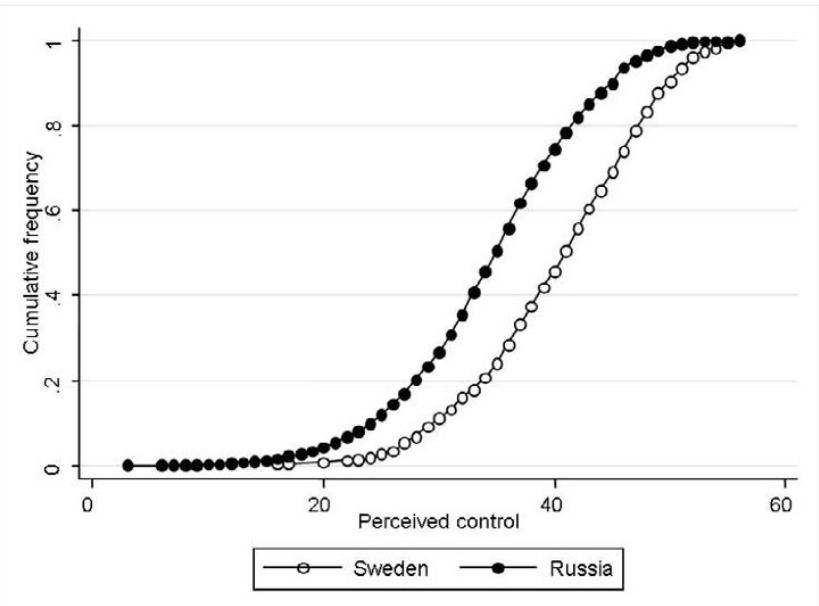

Figure I

Cumulative frequency of perceived control scores in Sweden and Russia.

cated Swedes while the lowest scores were found among Russians with low education (Figure 2). Widowed women had the lowest control score among the total Swedish population, but their score was still higher than the total mean score of Russian women. Widowed men had the lowest control score in the Russian sample. Control levels were also, in general, decreasing with higher age, except for Swedish men who instead seem to increase their control levels up to 55-59 years of age before declining.

\section{Analysis of individual control items}

Country and sex specific comparisons of each of the control items are presented in Table 3. There were substantial

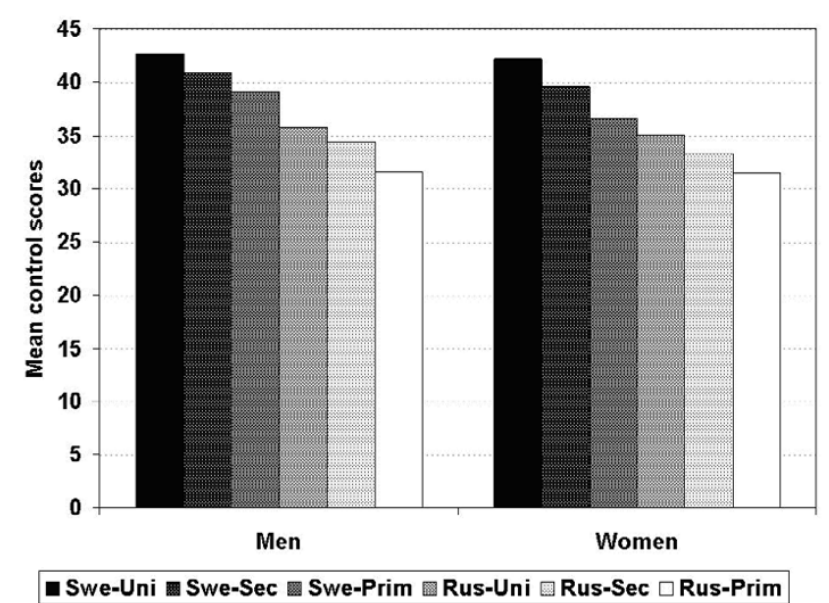

Figure 2

Mean control score per level of education for men and women in Sweden and Russia. differences (diff $>0.50$ ) in both health-related control items and life control items, with nearly all items showing higher control in Sweden than in Russia. The largest difference between the populations altogether is found among men and women on item 4 - "There are certain things I can do for myself to reduce the risk of getting cancer" - where the Russians are highly negative. They are also more negative when it comes to their chances of reducing the risk of a heart attack (item 3). However, the Russians (especially the women) are more positive than the Swedes on item 2 - "Keeping healthy depends on things that I can do". Further, Russian men and women believe to a substantially lower extent than do Swedes that they will have more positive than negative experiences in the future. The Russians also report lower scores in relation to often being treated unfairly, and that the past ten years have been full of changes without their knowing of what will happen next. However, Russians report that they feel in control at home almost just as much as Swedes, and they seem to find more meaning in their daily life than do Swedes. The lowest mean rates in both populations and for both sexes on any item were found for control over life events (item 5), followed by control over the future during the past 10 years (item 8 ).

\section{Associations between perceived control and self-rated health}

Table 4 shows results from logistic regression in two stages of adjustment. In the age-adjusted analyses, the OR of poor self-rated health was increased in groups with low perceived control in all four subgroups ( $\mathrm{p}$-value for test for trend in ORs $<0.001$ in all 4 groups). Controlling for covariates reduced the odds ratios (3.45 and 4.26 for Swedish men and women, respectively, and 2.61 and 3.74 for Russian men and women, respectively) but the associations remained highly significant. Although the effect of perceived control slightly differs for Sweden and Russia, the statistical interaction between country and control score was not significant either for men or women.

\section{Discussion}

This comparison of two community samples from Sweden and Russia represents two contrasting political and socio-cultural environments. We found that Russians reported lower perceived control on most items, and that they also reported poorer self-rated health than the Swedes. In both countries, perceived control was associated with poor self-rated health.

\section{Control and self-rated health}

The findings of low perceived control and self-rated health in Russia, as compared to Sweden, is in line with an earlier study by Carlson [30]. However, to our knowledge, no other studies have examined perceived control from an East-West perspective. Furthermore, while the Carlson 
Table 2: Age, sex, education and civil status specific scores of perceived control

\begin{tabular}{|c|c|c|c|c|c|c|c|c|}
\hline \multirow[b]{3}{*}{ Control } & \multicolumn{4}{|c|}{ LSH - Sweden } & \multicolumn{4}{|c|}{ HAPIEE - Russia } \\
\hline & \multicolumn{2}{|c|}{ Men } & \multicolumn{2}{|c|}{ Women } & \multicolumn{2}{|c|}{ Men } & \multicolumn{2}{|c|}{ Women } \\
\hline & & Alpha & & Alpha & & Alpha & & Alpha \\
\hline Sum score -mean & 40.56 & 0.66 & 39.00 & 0.71 & 34.51 & 0.64 & 33.59 & 0.63 \\
\hline$-S D$ & 7.20 & & 8.06 & & 8.00 & & 7.94 & \\
\hline \multicolumn{9}{|l|}{ Age } \\
\hline $45-49$ & 40.32 & 0.71 & 40.24 & 0.70 & 36.74 & 0.60 & 35.45 & 0.63 \\
\hline $50-54$ & 40.77 & 0.67 & 41.13 & 0.73 & 35.45 & 0.59 & 34.88 & 0.63 \\
\hline $55-59$ & 42.67 & 0.58 & 39.49 & 0.71 & 34.79 & 0.64 & 33.60 & 0.65 \\
\hline $60-64$ & 40.67 & 0.69 & 37.61 & 0.69 & 33.98 & 0.65 & 32.76 & 0.58 \\
\hline $65-69$ & 38.17 & 0.66 & 36.53 & 0.67 & 32.34 & 0.64 & 31.64 & 0.61 \\
\hline$p^{*}$ & 0.001 & & $<0.001$ & & $<0.001$ & & $<0.001$ & \\
\hline \multicolumn{9}{|l|}{ Education } \\
\hline Primary or less & 39.10 & 0.61 & 36.61 & 0.66 & 31.57 & 0.74 & 31.53 & 0.69 \\
\hline Secondary/Vocational & 40.89 & 0.65 & 39.53 & 0.70 & 34.38 & 0.60 & 33.28 & 0.63 \\
\hline University & 42.60 & 0.73 & 42.23 & 0.73 & 35.79 & 0.62 & 35.06 & 0.61 \\
\hline$p^{*}$ & $<0.001$ & & $<0.001$ & & $<0.001$ & & $<0.001$ & \\
\hline \multicolumn{9}{|l|}{ Civil status } \\
\hline Married/cohabiting & 40.91 & 0.67 & 39.65 & 0.72 & 34.81 & 0.63 & 34.26 & 0.62 \\
\hline Single & 37.19 & 0.78 & 39.46 & 0.63 & 33.18 & 0.72 & 32.65 & 0.63 \\
\hline Divorced & 40.22 & 0.53 & 37.19 & 0.72 & 33.17 & 0.63 & 33.09 & 0.65 \\
\hline Widowed & $39.48 * *$ & 0.61 & 34.12 & 0.71 & 30.77 & 0.68 & 32.26 & 0.64 \\
\hline$p^{*}$ & 0.07 & & 0.003 & & $<0.001$ & & $<0.001$ & \\
\hline
\end{tabular}

Alpha = Cronbach alpha

* p-value for one-way ANOVA

** only 4 individuals

study used a one-item measure of "life control", graded from 1 to 10 , the measure of perceived control used here is a more complex instrument counting 11 sub-items.

We noticed differences in control levels between sociodemographic groups within both populations, most visibly so in women who generally reported lower levels of control than men. Our findings of lower perceived control among the lower educated, the elderly and single people in both populations are in line with earlier reports on social status and psychosocial factor prevalence $[7,12,13,31,32]$. Furthermore, assumptions of a social gradient over the continent [1] was supported by our data, as perceived control was lowest among men and women with the lowest level of education in Russia, and highest among people with high education in Sweden (Figure 2). We used education as an indicator for social position although it is possible that other indicators, such as income, could be strongly related to control. However, unfortunately, data on income were not available in this analysis.

We also found significant associations between perceived control and self-rated health in both sexes in both populations. This is again in line with the studies by Carlson [30] and Bobak et al. [13], who found that life control had a similar effect on self-perceived health in different countries. Although Carlson concluded that control alone is unlikely to explain the East-West health divide, all these results suggest that that perceived control does have an evident impact on health, and that further studies on this aspect of individuals' lives are required.

\section{Differences in control by age and sex}

Control decreased with age, but there were differences between the populations. There was a linear decrease for both men and women in Russia, but not in Sweden where the decrease for men starts after the age of 60, and in Swedish women after the age of 55 . This suggests a faster decline in Russia, which is in line with earlier studies on self-rated health and physical functioning in Russia and Sweden [5]. Until the age of 55-59 years in men and 5054 years in women, the prevalence of poor health were similar in the two populations, but after those ages, poor health increased rapidly in Russia. A similar pattern was found by Andreev et al [2] on healthy life expectancy in Russia and Western Europe.

Russian women stand out as suffering from worse health conditions compared to all other groups in our analysis. Their levels of poor self-rated health are significantly worse than those of any other group. Suggesting that 
Table 3: Country and sex specific comparison of control items

\begin{tabular}{|c|c|c|c|c|c|c|c|c|}
\hline \multirow[b]{2}{*}{ Item } & \multicolumn{4}{|c|}{ Men } & \multicolumn{4}{|c|}{ Women } \\
\hline & Swe & Rus & $\begin{array}{c}\text { Diff } \\
(95 \% \mathrm{Cl})\end{array}$ & $\begin{array}{l}\text { P-value for } \\
\text { difference }\end{array}$ & Swe & Rus & $\begin{array}{c}\text { Diff } \\
(95 \% \mathrm{Cl})\end{array}$ & $\begin{array}{l}\text { P-value for } \\
\text { difference }\end{array}$ \\
\hline & mean & mean & & & mean & mean & & \\
\hline $\begin{array}{l}\text { Item I At home, I feel I have control over what } \\
\text { happens in most situations }\end{array}$ & 4.38 & 4.23 & $0.15(0.04,0.26)$ & 0.007 & 4.32 & 4.25 & $\begin{array}{c}0.07 \\
(-0.04,0.18)\end{array}$ & 0.21 \\
\hline $\begin{array}{l}\text { Item } 2 \text { Keeping healthy depends on things that I } \\
\text { can do }\end{array}$ & 4.03 & 4.09 & $\begin{array}{c}-0.06 * * \\
(-0.18,0.06)\end{array}$ & 0.32 & 3.81 & 4.13 & $\begin{array}{c}-0.32^{* *} \\
(-0.43,-0.20)\end{array}$ & $<0.001$ \\
\hline $\begin{array}{l}\text { Item } 3 \text { There are certain things I can do for myself } \\
\text { to reduce the risk of a heart attack }\end{array}$ & 4.37 & 3.38 & $0.99(0.84,1.14)$ & $<0.00 I^{\prime}$ & 4.37 & 3.55 & $0.82(0.68,0.96)$ & $<0.001$ \\
\hline $\begin{array}{l}\text { Item } 4 \text { There are certain things I can do for myself } \\
\text { to reduce the risk of getting cancer }\end{array}$ & 3.62 & 2.13 & $1.49(1.32,1.67)$ & $<0.001$ & 3.50 & 2.28 & $1.22(1.05,1.39)$ & $<0.001$ \\
\hline $\begin{array}{l}\text { Item } 5^{*} \text { I feel that what happens in my life is often } \\
\text { determined by factors beyond my control }\end{array}$ & 2.21 & 1.81 & $0.40(0.25,0.54)$ & $<0.001$ & 1.94 & 1.60 & $0.34(0.20,0.47)$ & $<0.001$ \\
\hline $\begin{array}{l}\text { Item } 6 \text { Over the next } 5-10 \text { years } I \text { expect to have } \\
\text { many more positive than negative experiences }\end{array}$ & 3.91 & 3.02 & $0.89(0.73,1.05)$ & $<0.001$ & 3.96 & 3.11 & $0.85(0.69,1.01)$ & $<0.001$ \\
\hline $\begin{array}{l}\text { Item } 7 * \text { I often have the feeling that I am being } \\
\text { treated unfairly }\end{array}$ & 3.95 & 2.88 & $1.07(0.92,1.22)$ & $<0.001$ & 3.76 & 2.66 & $1.09(0.93,1.25)$ & $<0.001$ \\
\hline $\begin{array}{l}\text { Item } 8^{*} \text { In the past ten years my life has been full } \\
\text { of changes without my knowing what will happen } \\
\text { next }\end{array}$ & 2.68 & 1.90 & $0.78(0.61,0.95)$ & $<0.001$ & 2.19 & 1.69 & $0.50(0.34,0.67)$ & $<0.001$ \\
\hline $\begin{array}{l}\text { Item } 9 * \text { I very often have the feeling that there's } \\
\text { little meaning in the things I do in my daily life }\end{array}$ & 3.33 & 3.78 & $\begin{array}{c}-0.46 * * \\
(-0.6 I,-0.3 I)\end{array}$ & $<0.001$ & 3.25 & 3.48 & $\begin{array}{c}-0.23^{* *} \\
(-0.39,-0.07)\end{array}$ & 0.005 \\
\hline $\begin{array}{l}\text { Item } 10^{*} \text { I sometimes feel as if I've done all there is } \\
\text { to do in life }\end{array}$ & 3.86 & 3.59 & $0.28(0.12,0.43)$ & $<0.001$ & 3.87 & 3.43 & $0.44(0.28,0.60)$ & $<0.001$ \\
\hline $\begin{array}{l}\text { Item II* I gave up trying to make big } \\
\text { improvements or changes in my life a long time } \\
\text { ago }\end{array}$ & 4.18 & 3.68 & $0.50(0.35,0.65)$ & $<0.001$ & 4.02 & 3.41 & $0.61(0.44,0.77)$ & $<0.001$ \\
\hline
\end{tabular}

*item used in reverse order in the table to have 0 as low control and 5 as high control

** items in italics are those with higher control among Russian subjects

Table 4: The association between self-rated health and perceived control in both samples (country-specific quartiles)

\begin{tabular}{|c|c|c|c|c|}
\hline & \multicolumn{2}{|c|}{ Age-adjusted } & \multicolumn{2}{|c|}{ Fully adjusted* } \\
\hline & Sweden & Russia & Sweden & Russia \\
\hline \multicolumn{5}{|l|}{ Men } \\
\hline IQ (low control) & $3.95(2.2 \mathrm{I}-7.07)$ & $2.87(2.19-3.75)$ & $3.45(1.77-6.70)$ & $2.61(1.98-3.45)$ \\
\hline $2 Q$ & $3.19(1.81-5.61)$ & $1.57(1.24-1.97)$ & $2.24(1.20-4.20)$ & $1.46(1.16-1.85)$ \\
\hline $3 Q$ & $1.84(1.09-3.10)$ & $1.17(0.95-1.45)$ & $1.51(0.85-2.70)$ & $1.15(0.93-1.43)$ \\
\hline 4Q (high control) & I & 1 & I & I \\
\hline$P$ for trend** & $<0.001$ & $<0.001$ & $<0.001$ & $<0.001$ \\
\hline \multicolumn{5}{|l|}{ Women } \\
\hline IQ (low control) & $5.44(2.83-10.47)$ & $4.30(2.87-6.44)$ & $4.26(2.07-8.78)$ & $3.74(2.48-5.64)$ \\
\hline $2 \mathrm{Q}$ & $5.11(2.78-9.38)$ & $2.72(1.98-3.76)$ & $5.06(2.59-9.90)$ & $2.53(1.83-3.51)$ \\
\hline $3 Q$ & $3.22(1.82-5.68)$ & $2.08(1.51-2.87)$ & $3.42(I .83-6.4 I)$ & $2.00(1.45-2.78)$ \\
\hline 4Q (high control) & $\mathrm{I}$ & 1 & $\mathrm{I}$ & I \\
\hline$P$ for trend ${ }^{* *}$ & $<0.001$ & $<0.001$ & $<0.001$ & $<0.001$ \\
\hline
\end{tabular}

* adjusted for age, education, civil status, BMI, smoking, blood pressure and cholesterol

** test for linear trend in log-odds of poor self-rated health (following Mantel [48])

$\mathrm{Q}=$ quartile 
health levels may depend on - or reflect - different reactions to adversities among the sexes in Russia, Andreev et al. [2] imply in their study on health expectancy in Russia, that although the premature male mortality in Russia is the most striking feature of the nation's health development, there also appears to be a substantial burden of illhealth among women - "men die while women suffer".

\section{Sub-item analysis of perceived control}

Regarding the sub-item analysis of perceived control, according to traditional views on psychometrics, there may be reasons for keeping sub-items together as an instrument and not analyze these questions separately [33]. However, since earlier studies have settled for oneitem control questions [6] or have used the perceived control instrument without any sub-item analysis $[12,13]$, one of our aims was to shed more light on what differences may exist on sub-item level while having access to several control questions. This can be seen more as an explorative analysis rather than an actual confirmative study.

The whole concept of perceived control is closely related to the discussion of locus of control, and whether it is external or internal. Locus of control is usually described as the tendency in an individual to perceive a causal relationship between his/her own behaviour and what happens to him. Internal locus of control places the agent in an active role - the individual can take action over their own lives - while an external locus of control means that power over life lies outside of one's authority $[34,35]$. The perceived control instrument is designed to capture aspects of internal locus of control rather than that of an external locus [10]. A study by Leinsalu [34] used measures of locus of control to study differences in self-rated health by various dimensions of the social structure in Estonia. Leinsalu found that locus of control was strongly related to poor self-rated health, and that external locus of control was more prevalent among women but had a stronger association with poor self-rated health among men. However, to our knowledge, there are no studies that have investigated internal locus of control in an EastWest perspective.

There were no substantial differences in the reporting of feeling in control at home between the populations. It is possible that this reflects the fact that the home environment is not the major source of psychological distress. As for the health-related questions (items 2-4), it is somewhat contradictory that the Russians scored higher than the Swedes in believing that "keeping healthy" depends on things they can do, while on items 3 and 4 scoring immensely low on their options of preventing cancer or heart attack. Perhaps "keeping healthy" is associated with an unspecific "health" outcome, possibly including con- ditions such as obesity or injury, whereas cancer and heart attack may be seen as external threats, impossible to overcome. If so, this should be a logic reaction, considering the high death rates in Russia, especially from heart disease $[1,4]$. Russians also scored better than the Swedes on the item regarding meaning in daily life; one could speculate that this difference may reflect the influence of collectivism that has prevailed since socialist days whereas Sweden in comparison since long is a secularized and individualized society.

\section{Learned helplessness - another aspect of control measures}

The fact that more Swedes than Russians in our populations think that the next 5-10 years will give them more positive than negative experiences, while the Russians to a higher extent than Swedes believe that they are often being treated unfairly, could probably be seen as reflecting differences in the respective political systems of the populations, with differences in actual options of taking action and proposing changes [24-26], but it could also be a sign of learned expectation levels [36]. Several studies have shown that people in lower socioeconomic positions may experience psychosocial strain to a higher extent than those better off $[7,31,32,37]$. Different patterns of socialisation, when people notice that there is no relationship between their responses and the outcome, could lead to fatalism and expectations of having low prospects for the future, as well as inherited or learned coping strategies $[15,36,38,35,14,39]$. It is plausible that these coping mechanisms could also apply in whole populations; this could partly explain why the Russians score so low on the control items mentioned above. This is also consistent with the fact that the lowest mean rates for both populations on any item were found for control over life events, followed by control over the future during the past 10 years, both again possibly reflecting the uncertainties of societal changes and individual attitudes towards these.

\section{Psychosocial resources and intervention strategies}

Reduction of social polarisations and increasing capacity from social environment to enhance positive outcome expectancies is what is aimed at in international and national targets for health e.g. the basis for the Ottawa manifest with its focus on health oriented policies and arena perspectives [40]. Above reduction of material deprivation, interventions in terms of empowerment strategies that build on the ambition to enhance individual chances of developing positive expectancies of the future, hope, self esteem and trust are fundamental [41]. The European Network of Health Promoting Agencies noted positive side effects in a project aiming at behavioural change, where people involved in planning and implementing the project reported increased levels of social integration and assertiveness [42]. 


\section{Methodological issues and limitations of the study}

There are several problems with a study of this type. First, temporality of the association between perceived control and self-rated health is hard to establish in cross-sectional data. Prospective studies are needed to further validate these associations. Although two prospective studies found association between perceived control and mortality $[16,17]$, a reverse causation of the relation between control and self-rated health cannot be excluded. As both the LSH and the HAPIEE projects are originally designed as prospective studies, we will revisit this analysis when follow-up data are available and look at the temporal associations.

Second, there is the general problem with validity of selfreported measures. Kristenson [35] has pointed out that a correlation between self-reported psychological measures and self-reported health could merely reflect an overlap between these measures, with results instead depending on some other common factor. While there are some studies that have suggested that self-rated health may partly reflect a sense of control $[12,43]$, most studies have continued to use them as non-interfering variables in order to be comparable with earlier research.

To account for possible overlap between control and selfrated health, we have repeated the analysis with a control scale excluding three health-related items (items 2, 3, 4; see Table 3 for the exact wording of the items). The results did not substantially change when we excluded these three items although we can say that the results of the effects of this new control scale on self-rated health are now very similar in all four gender-country specific groups. In the fully adjusted analyses, the OR of poor selfrated health was increased in groups with low perceived control in all four subsamples ( $\mathrm{p}$-value for test for trend in ORs $<0.001$ in all 4 subsamples). Those in the lowest quartile of control were approximately three times more likely to report poor self-rated health than those in the highest quartile of control (3.37 and 3.51 for Swedish men and women, respectively, and 3.28 and 3.41 for Russian men and women, respectively).

Third, chronic disease is a possible confounder in the relationship between control and health because an existing disease can reduce the feeling of control and self-perceived health. To account for this possible effect, we have conducted additional analysis excluding people who reported myocardial infarction, angina and stroke in the past. Results from our original analysis and new results were virtually same. This suggests that chronic disease (although expressed only in terms of cardiovascular disease) was not major confounding factor in this analysis
Fourth, psychosocial determinants of self-rated health may differ by age group. We believe that we have included the relevant age groups for this kind of study. Siegrist \& Marmot [44] refer to the fact that midlife is the period of life, after the first year of life, during which social inequalities in health manifests themselves most strongly. This is in line with our data selection, comprising data on men and women aged 45-69 in Sweden and Russia.

Fifth, the HAPIEE sample possibly suffers from a health selection due to the fact that the study took part in a clinic. This is reflected by a better than expected levels of physical functioning (unpublished data), compared to data collected previously [5]. However, this bias would lead to overestimation of both control and health, and result in underestimation of the differences between Sweden and Russia.

The mode of administration of the questionnaires differed between countries, with self-reports in Sweden and interviewer-administered in Russia. There is evidence that using an interviewer may lead to under-reporting depression [45] or other self reported health outcomes [46,47] but we found higher levels of poor self-reported health and lower scores of control in Russia.

Sixth, non-response bias should also be considered. In general, people who participate in health surveys are healthier than those who do not. Thus, the levels of poor self-rated health in our study are probably underestimated. However, assuming that the differences between respondents and non-respondents were similar in both countries, the comparisons between the populations are valid, even if the absolute prevalence rates were underestimated (difference in response rates in both samples is approximately $1 \%$ ). The non-response bias should not affect the association between self-rated health and perceived control within the study sample.

\section{Conclusion}

In conclusion, levels of both perceived control and selfrated health are lower in Russia than in Sweden, and this is likely to reflect the differences in health status and in the social and psychosocial environments between the two countries. Within both populations, perceived control was strongly associated with self-rated health. Although the cross-sectional design does not allow causal inference, these results support the view that perceived control influences health and that it may mediate the association between socioeconomic hardship and health.

\section{Competing interests}

The author(s) declare that they have no competing interests. 


\section{Authors' contributions}

JL participated in the acquisition and analyses of data, and drafted the manuscript. HP and MB participated in the design and coordination of the HAPIEE study, conducted analyses and helped draft the manuscript. SM participated in the design and coordination of the HAPIEE study and helped draft the manuscript. MK participated in the design of the LSH study, acquisition and analyses of data, and helped draft the manuscript. All authors read and approved the final manuscript.

\section{Acknowledgements}

The HAPIEE study is funded by grants from the Wellcome Trust "Determinants of Cardiovascular Diseases in Eastern Europe: A multi-centre cohort study" (grant no. 064947/Z/9I/Z), a grant from the US National Institute for Aging "Health disparities and aging in societies in transition (the HAPIEE study)" (grant no. IROI AG23522-0I), and a grant from the MacArthur Foundation (Health and Social Upheaval Network).

The LSH study is funded by the Swedish Research Council (2004- I88I), the Swedish Heart and Lung Foundation (20040530). Grants from Linkoping University and the County of Ostergotland were provided via two joint strategic programmes: CIRC (Cardiovascular Inflammation Research Center) and the Department of Health and Society.

We would like to thank local collaborators in Novosibirsk and southeast Sweden for their enormous contributions.

\section{References}

I. Bobak M, Marmot M: East-West mortality divide and its potential explanations: proposed research agenda. BMJ 1996, 3 I 2:42 I-425.

2. Andreev EM, McKee M, Shkolnikov VM: Health expectancy in the Russian Federation: a new perspective on the health divide in Europe. Bulletin of the World Health Organization 2003, 8I:778-787.

3. McMichael AJ, McKee M, Shkolnikov V, Valkonen T: Mortality trends and setbacks: global convergence or divergence? Lancet 2004, 363:1155-1159.

4. Men T, Brennan P, Boffetta P, Zaridze D: Russian mortality trends for 199I-200I: analysis by cause and region. BMJ 2003, 327:964.

5. Bobak M, Kristenson M, Pikhart H, Marmot M: Life span and disability: a cross sectional comparison of Russian and Swedish community based data. BMJ 2004, 329:767.

6. Carlson P: Self-perceived health in East and West Europe: another European health divide. Social Science and Medicine 1998, 46: I355-1366.

7. Kristenson M, Kucinskiene Z, Bergdahl B, Calkauskas H, Urmonas V, Orth-Gomer K: Increased psychosocial strain in Lithuanian versus Swedish men: the LiVicordia study. Psychosom Med 1998, 60:277-282.

8. Syme SL: Control and health: a personal perspective. In Stress, Personal Control and Health Edited by: Steptoe A and Appels A. Brussels-Luxembourg, John Wiley \& Sons Ltd; 1989:3-18.

9. Marmot MG, Davey Smith G, Stansfeld S, Patel C, North F, Head J, White I, Brunner E, Feeney A: Health inequalities among British civil servants: the Whitehall II study. Lancet 1991, 337:1387-1393.

10. Multiple paths of midlife development Edited by: Lachman ME and Boone James J. Chicago, The University of Chicago Press; 1997-490.

II. Lachman ME, Weaver SL: The sense of control as a moderator of social class differences in health and well being. J Pers Soc Psychol 1998, 74:763-773.

12. Bobak M, Pikhart H, Hertzman C, Rose R, Marmot M: Socioeconomic factors, perceived control and self-reported health in Russia. A cross-sectional survey. Soc Sci Med 1998, 47:269-279.
13. Bobak M, Pikhart H, Rose R, Hertzman C, Marmot M: Socioeconomic factors, material inequalities, and perceived control in self-rated health: cross-sectional data from seven post-communist countries. Social Science and Medicine 2000, 5 I: I 343-I 350.

14. Kristenson M, Eriksen HR, Sluiter JK, Starke D, Ursin H: Psychobiological mechanisms of socioeconomic differences in health. Social Science and Medicine 2004, 58: I5 I I-I522.

15. Skinner EA: A guide to constructs of control. J Pers Soc Psychol 1996, 7 1:549-570.

16. van Lenthe FJ, Schrijvers CTM, Droomers M, Joung IMA, Louwman $\mathrm{MJ}$, Mackenbach JP: Investigating explanations for socioeconomic inequalities in health. European Journal of Public Health 2004, I 4:63-70.

17. Bosma H, Schrijvers C, Mackenbach JP: Socio-economic inequalities in mortality; importance of perceived control. BMJ 1999, 319:1469-1470.

18. Social determinants of health Edited by: Marmot MG and Wilkinson RG. New York, Oxford University Press; 2000.

19. Marmot M, Wilkinson RG: Psychosocial and material pathways in the relation between income and health: a response to Lynch et al. BMJ 200I, 322:1233-I236.

20. Kristenson M, Kucinskiene Z, Bergdahl B, Orth-Gomer K: Risk factors for coronary heart disease in different socioeconomic groups of Lithuania and Sweden - the LiViCordia Study. Scand J Public Health 200I, 29: I40-I50.

21. Marmot MG, Bosma H, Hemingway H, Brunner E, Stansfeld S: Contribution of job control and other risk factors to social variations in coronary heart disease incidence [see comments]. Lancet 1997, 350:235-239.

22. Rahkonen O, Laaksonen M, Martikainen P, Roos E, Lahelma E: Job control, job demands, or social class? The impact of working conditions on the relation between social class and health. $J$ Epidemiol Comm Health 2006, 60:50-54.

23. Gilmore $A B C$, McKee $M$, Rose R: Determinants of and inequalities in self-perceived health in Ukraine. Social Science and Medicine 2002, 55:2177-2188.

24. McKee M: Unraveling the enigma of the Russian mortality crisis: A review essay. Population and Development Review 1999, 25:36I-366.

25. McKee M: Commentary: Health and economic transition. Int J Epidemiol 2005, 34: I203-I 206.

26. Cockerham WC, Snead MC, Dewaal DF: Health lifestyles in Russia and the socialist heritage. J Health Soc Behav 2002, 43:42-55.

27. Peasey A, Bobak M, Kubinova R, Malyutina S, Pajak A, Tamosiunas A, Pikhart H, Nicholson A, Marmot M: Determinants of cardiovascular disease and other non-communicable diseases in Central and Eastern Europe: rationale and design of the HAPIEE study. BMC Public Health 2006, 6:255.

28. Lachman ME: Development in midlife. Annu Rev Psychol 2004, 55:305-331.

29. Ware JE, Sherbourne CD: The MOS 36-item short-form health survey (SF-36). I. Conceptual framework and item selection. Med Care 1992, 30:473-483.

30. Carlson P: Self-perceived health in East and West Europe. Another European health divide. Soc Sci Med 1998, 46: $1355-1366$.

31. Siegrist J, Peter R, Junge A, Cremer P, Seidel D: Low status control, high effort at work and ischemic heart disease: prospective evidence from blue-collar men. Social Science and Medicine 1990, 31:I I27-II34.

32. Taylor SE, Seeman TE: Psychosocial resources and the SEShealth relationship. Annals of the New York Academy of Sciences 1999, 896:225

33. Bowling A: Measuring health. A review of quality of life measurement scales. Philadelphia, Open University Press; 1997.

34. Leinsalu M: Social variation in self-rated health in Estonia: A cross-sectional study. Social Science and Medicine 2002, 55:847-861.

35. Kristenson M: Socio-economic position and health - the role of coping. In Social inequalities in health - new evidence and policy implications Edited by: Marmot MG and Siegrist J. New York, Oxford University Press; 2006: 127-153.

36. Ursin H, Eriksen HR: The cognitive activation theory of stress. Psychoneuroendocrinology 2004, 29:567-592.

37. Sjogren E: Psychosocial factors in adult life in relation to gender, biological markers of stress and self-rated health. 
Department of Health and Society, Linkoping University, Sweden; 2005.

38. Thrane C: Explaining educational-related inequalities in health: mediation and moderator models. Social Science and Medicine 2006, 62:467-478.

39. Bosma H: Socio-economic differences in health: Are control beliefs fundamental mediators? In Social inequalities in health - new evidence and policy implications Edited by: Marmot MG and Siegrist J. New York, Oxford University Press; 2006:153-167.

40. Organisation WH: Ottawa Charter for Health Promotion Copenhagen, WHO Europe; 1986.

4I. Rappaport J: Terms of Empowerment/Exemplars of Prevention. American Journal of Community Psychology 1987, I 5: I 21- I 48.

42. Siegrist J, Joksimovic L: Sozial Ungleichheit und Gesundheit in Europa. Teilbericht Deutschland. Koln, BZgA; 200I.

43. Mellner C: Women's subjective and objective health over time: The role of psychosocial conditions and physiological stress responses. Department of Psychology, Stockholm University; 2004.

44. Siegrist J, Marmot M: Health inequalities and the psychosocial environment-two scientific challenges. Social Science and Medicine 2004, 58: | $463-1473$.

45. Chan KS, Orlando M, Ghosh-Dastidar B, Duan N, Sherbourne CD The interview mode effect on the Center for Epidemiological Studies Depression (CES-D) scale: an item response theory analysis. Med Care 2004, 42:28I-289.

46. Moum TA: Mode of administration and response style effects in self-reported health and health behavior: An experimenta broad-population study. Presented at the National Conference on Sociology, Longyearbyen, Spitsbergen, Norway.; 1998.

47. Moriarty DG, Zack MM, Kobau R: The Centers for Disease Control and Prevention's Healthy Days Measures - Population tracking of perceived physical and mental health over time. Health and Quality of Life Outcomes 2003, I:37.

48. Mantel N: Chi-square tests with one degree of freedom: extensions of the Mantel-Haenszel procedure. J Am Stat Assoc 1963, 58:700.

\section{Pre-publication history}

The pre-publication history for this paper can be accessed here:

http://www.biomedcentral.com/1471-2458/7/314/pre

pub
Publish with Bio Med Central and every scientist can read your work free of charge

"BioMed Central will be the most significant development for disseminating the results of biomedical research in our lifetime. "

Sir Paul Nurse, Cancer Research UK

Your research papers will be:

- available free of charge to the entire biomedical community

- peer reviewed and published immediately upon acceptance

- cited in PubMed and archived on PubMed Central

- yours - you keep the copyright 